\title{
HOME MECHANICAL VENTILATION OF CHILDREN
}

Virginia S Nelson

Julie C Carroll

Edward A Hurvitz

Janet $M$ Dean
Within the past decade, it has become increasingly common for children to use mechanical ventilation in their homes, schools and communities. This has become possible because of improved management of chronic illness and acute injury, the development of more portable ventilators, and the growth of rehabilitation technology.

The growth of the population of children with respiratory problems has resulted in the development of home ventilator programs at many tertiary hospitals to meet the complex medical needs associated with ventilator dependence. At the University of Michigan Medical Center, a team of physiatrists, pulmonary specialists, rehabilitation nurses, speech pathologists, social workers, psychologists, occupational therapists, physical therapists and respiratory therapists work together to provide the care that these children require. A formal program also helps patients and their families to meet others who are similarly affected.

The modern approach has been advocated since the early 1980s (Koop 1983). The early literature on home mechanical ventilation focused primarily on reviews of various populations of ventilatorassisted individuals, generally followed by recommendations on how a program ought to be designed (Splaingard et al.
Sivak et al. 1986, White and Perez 1986, Peters and Viggiano 1988, Whitford 1988, Gillis et al. 1989, Goldberg and Monahan 1989, Goldberg and Frownfelter 1990). Other reports described a national approach, and outlined problems in the existing programs (Goldberg 1986, American Thoracic Society 1989, Plummer et al. 1989). Reports by Strumpf (1990) and Waldhorn (1992) focused on new developments in ventilator technology.

Much attention has been paid to ethics: attempting to define the situations in which home mechanical ventilation is beneficial, by evaluating the psychosocial, financial and medical impact on the child and family (Stein and Jessop 1984, Purtilo 1986, Aday et al. 1989, Gilgoff et al. 1989, Hazlett 1989, Merkens et al. 1989, Quint et al. 1990, Thompson and Richmond 1990, Bach 1991, Marcus et al. 1991, Warzak et al. 1991). Many of these studies indicated that quality of life is better when children are cared for at home, yet they also acknowledged the continuing stress of caring for a medically fragile child. We could not find any reports dealing with the roots of this stress, how they may be modified, or how the ventilatorassisted population may change over time. Since one purpose of a program of pediatric and adolescent home ventilation is to simplify continuing care and normalize 


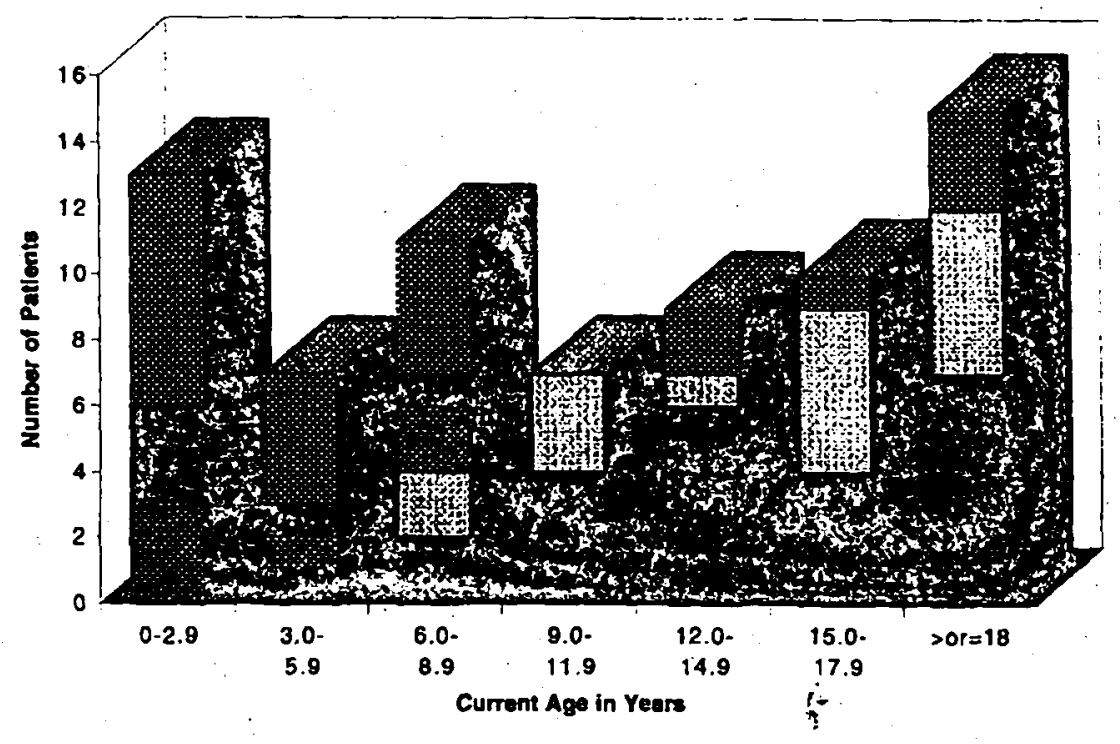

the lives of patients and their families as much as possible, we reviewed the changes in this ventilator-assisted population in the past 15 years, paying special attention to stressors and the complications of home care.

\section{Method}

The study included all patients assisted by home mechanical ventilation seen through the University of Michigan Pediatric and Adolescent Home Ventilator program between January 1978 and March 1993. We used hospital charts to obtain information about the initial hospital stay, discharge home and subsequent hospitalizations. Information about schooling, nursing hours and other variables not in the hospital medical chart was obtained from nursing records. Ventilator parameters were obtained from respiratory therapy records. Financial resource information was retrieved from hospital charts or socialwork records. Children who had died, been weaned from ventilation or lost to follow-up since they were first seen were included in the initial and discharge data. The children who had been weaned, but were still followed through our ventilator clinic were not included in data about the current status of the group.

Eighty-nine patients $(31$ females and 58 males) met the criteria for the study.
The average age at the time of the study was 11.3 (range 1.0 to 29.2 ) years. The median age was 9.7 years (Fig. 1). Children had been at home for an average of 3.3 (range 0.1 to 14.0 ) years at the time of this review (spring 1993): 87 had been discharged to their natural parents, and two, to foster homes. Five patients were lost to follow-up. At the time of the study four patients had been weaned off the ventilator, 12 had died and five had been lost to follow-up, leaving 68 available for data collection.

\section{Results}

MEDICAL DEMOGRAPHIÇS

The medical parameters of our groups of patients were similar to those of other populations described in the literature.

\section{Primary diagnoses and reasons for mechanical ventilation}

The largest diagnostic groups were spinal cord injury (SCI) and myopathy $(34 \%$ and $21 \%$, respectively). Bronchopulsmonary dysplasia (BPD) accounted for $8 \%$, and congenital central hypoventilation syndrome (CCHS) accounted for $7 \%$. There were many other diagnoses, including myelopathies, neuropathies, congenital malformations and cancers (Table I; Fig. 1). Of all the diagnoses in the patient population, $51 \%$ were of congenital and $49 \%$ were of acquired conditions. The most 
TABLE I

Primary diagnoses $(N=89)$ and hospital re-admissions

\begin{tabular}{lccc} 
Primary diagnosis & Patients & $\begin{array}{c}\text { Percentage } \\
\text { re-admitted }\end{array}$ & $\begin{array}{c}\text { Average re-admissions } \\
\text { per year per patient }\end{array}$ \\
\hline SCI & 30 & 43 & 0.9 \\
Myopathy & 19 & 47 & 1.7 \\
BPD & 7 & 57 & 3.4 \\
CCHS & 6 & 67 & 2.0 \\
Neuropathy & 5 & 80 & 1.0 \\
Myelopathy & 3 & 0 & 0.0 \\
Other & 19 & 42 & 2.3 \\
Total congenital & 45 & 56 & 1.7 \\
Total acquired & 44 & 43 & 1.5 \\
\hline
\end{tabular}

$\mathrm{SCI}=$ spinal cord injury; $\mathrm{BPD}=$ bronchopulmonary dysplasia; $\mathrm{CCHS}=$ congenital central hypoventilation syndrome.

common reason for using mechanical ventilation was neuromuscular dysfunction $(70 \%)$, followed by primary lung disease $(15 \%)$, airway problems or malformation of the trachea $(8 \%)$ and central hypoventilation $(7 \%)$. One patient was mechanically ventilated for both primary lung disease and an airway problem.

\section{Initial hospitalization}

The average age for the initiation of ventilation was 7.2 (range 0 to 21.3) years. The median age was 4.4 years (Fig. 2). Long-term mechanical ventilation was begun at birth in $24 \%$. The mean initial length of stay was 216 (range 2 to 968 ) days. The median was 182.5 days.

Children first ventilated at birth had the longest average hospital stay (253 days). Of these children, $53 \%$ had either BPD or CCHS. The remainder of this group had either congenital malformations or birth injuries. Children first ventilated between the ages of 1 month and 5 years had an average initial hospital stay of 232 days. Of this group, $38 \%$ had SCI, $29 \%$ had myopathy or neuropathy, and the remainder had congenital malformations, enzyme deficiencies or traumatic brain injuries.

Children first ventilated after 5 years of age had the shortest average hospital stay (176 days). Of these children, $77 \%$ had either SCI or myopathy. The remainder had either neuropathy, myelopathy or cancer. The $t$ test revealed a trend toward a longer initial hospitalization if patients were initially ventilated at or before age 5 years $(p<0.1)$ as opposed to after age 5 years. Of the major diagnostic groups, the children with BPD had the longest average hospital stay (326 days), followed by SCI (296 days), myopathy (121 days) and CCHS (70 days). A $t$ test showed a definite trend toward a longer initial hospital stay for those patients with SCI than for those with a myopathy $(p<0.1)$.

By the $t$ test, there was a statistically significant difference between the initial lengths of stay of patients discharged before 1990 (averaging 264 days) and those first discharged after that date (averaging 164 days) $(p<0.05)$. The average ages at the initiation of ventilation for these two groups were similar ( 7.0 years for patients discharged before 1990 and 7.3 years for those discharged after that time): but the diagnoses of these two groups were disparate. The proportion of patients with SCI in the group discharged before 1990 was more than twice as large as in the group discharged after that date. In addition, the proportion of patients discharged with BPD from 1 January 1990 was three times the proportion of the group discharged before then.

The majority of patients were discharged from the pediatric rehabilitation unit $(73 \%)$. Others were discharged from pediatric intensive care $(6 \%)$, neonatal intensive care $(6 \%)$ and adult intensive care $(1 \%) .14 \%$ of the children were initially discharged from outside hospitals. Most of the discharges from intensive 

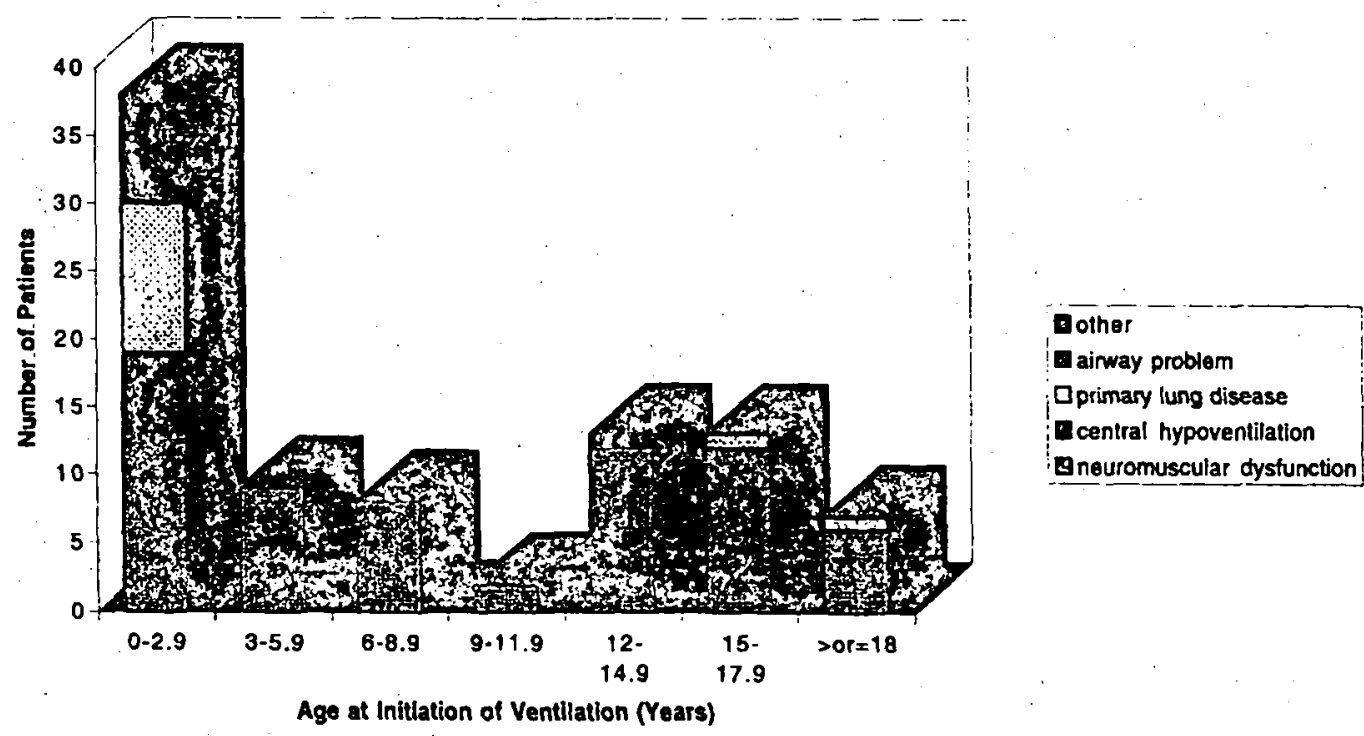

Fig. 2. Ages of patients at intiation of ventilation, and reason for ventilation.

TABLE II

Types of ventilation used

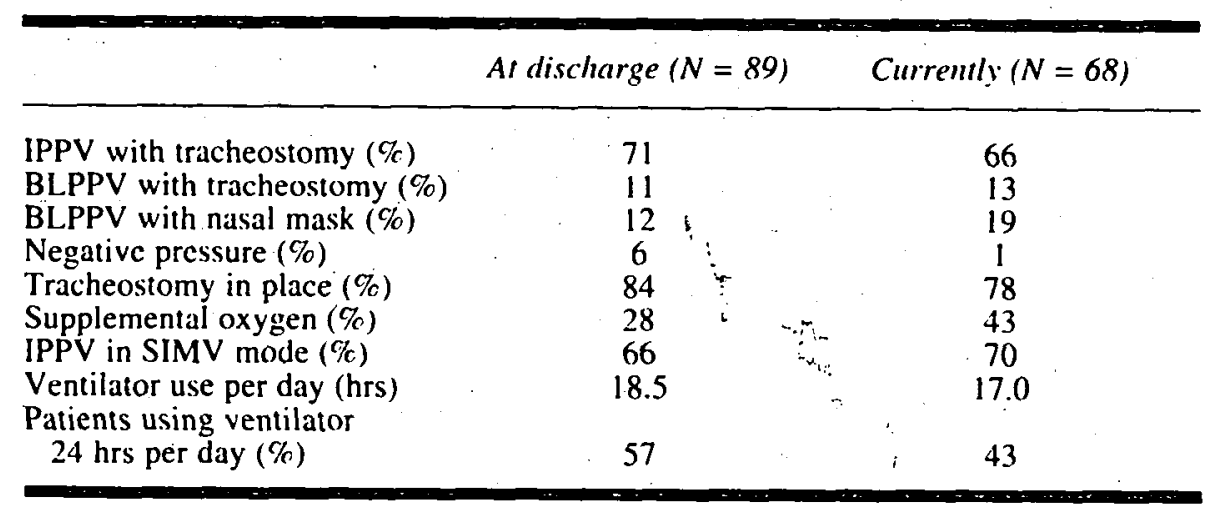

IPPV = intermittent positive pressure ventilation: $\mathrm{BLPPV}=$ bi-level positive pressure ventilation; SIMV = synchronized intermittent mandatory ventilation.

care units occurred before the formation of a stable ventilator unit within the pediatric rehabilitation unit.

\section{MODES OF VENTILATION}

At discharge, most of the patients were using intermittent positive pressure ventilation (IPPV) in the synchronized intermittent mandatory ventilation (SIMV) mode $(66 \%)$. By the time of the study, there was only a slight change in this group: $70 \%$ were still using IPPV in the SIMV mode. There was a slight increase between discharge and the time of the study in the number of patients using bilevel positive pressure ventilation with a nasal mask (from 12 to $19 \%$ ), and in the number of patients using bi-level positive pressure ventilation with a tracheostomy (from 11 to 13\%) (Table II). This increase includes two patients who formerly used IPPV and one patient who formerly used a pneumowrap. Two patients initially using bi-level positive pressure ventilation died. There was a noticeable change in the use of negative 
pressure ventilation: five patients used it at discharge and one used it at the time of the study. Of the four who stopped using negative pressure, one was weaned; two began using IPPV, and one began bi-level positive pressure ventilation. The one patient who continued to use her cuirass found it preferable to bi-level positive pressure ventilation by mask.

Between the patients' discharge and the time of the study, there was a slight decrease in the percentage of patients with tracheostomies (see Table II). The $\chi^{2}$ test showed a trend $(p<0.1)$ towards an increase in the number of patients requiring supplemental oxygen, from 28 to $43 \%$, which represents an increase of eight patients (three with SCI, four with myopathy and one with dwarfism). Only two patients initially using oxygen were weaned off it (one with myopathy and one with BPD). Two patients initially on oxygen died and two were weaned from the ventilator entirely.

At discharge, the patients used the ventilator an average of 18.5 (range 10 to 24) hours per day, while at the time of the study, this number was slightly smaller, at 17 (range 10 to 24 ) hours per day. The $\chi^{2}$ test also showed a trend $(p<0.1)$ towards a decrease in the proportion of patients using the ventilator 24 hours per day (from 57 to $43 \%$ ) (see Table II).

\section{DAILY LIFE}

\section{Nursing}

Of the 62 patients for whom data were available for both discharge and currently, 27 had a decrease in nursing hours, seven had an increase and 28 had the same number as at discharge. The patients in these groups had various diagnoses.

At discharge, the average number of hours per day of in-home nursing services for those families who used it was 17 (range 1 to 24). On average, patients using IPPV with tracheostomy had the most nursing hours (17.8). $25 \%$ of patients had a nurse in the home 24 hours per day.

At the time of the study, an average of 3.3 years post-discharge, the average number of nursing hours per day was 14.8 (range 1 to 24). Again, patients on average nursing hours (17.9) with $20.6 \%$ having a nurse in the home 24 hours per day.

At discharge, 11 patients chose to have all their care performed by members of their family. For nine of these, friends and family still perform all care. By the time of the study, slightly more patients $(23.8 \%)$ had chosen to have all care performed by family and/or friends. The six patients who no longer used outside nursing care included five with tracheostomies.

The 9- to 11.9-year age-group currently need the most hours of nursing, followed by the age-group 2.9 years or under. The diagnostic group requiring the most hours of nursing was children with SCI, followed by children with BPD.

\section{Nutrition}

At discharge, almost half of the patients (43\%) were able to eat orally. A further $23 \%$ could eat orally but also needed tube feedings. $34 \%$ were fed exclusively by tube. At the time of the study, slightly more of the patients $(47 \%)$ were eating orally. $31 \%$ ate orally with supplemental gastrostomy feedings. Substantially fewer (22\%) were fed exclusively by tube than at discharge. Most children $(76 \%)$ initially ventilated before age 3 were tube-fed at discharge, while only $44 \%$ of patients first ventilated over the age of 3 years were tube fed. By the $\chi^{2}$ test, this difference was statistically significant $(p<0.05)$. Fifty-one of the 67 patients for whom there are both discharge and current data had no change in their eating status. Four patients had a change in the type of tube used, four patients started using a tube, and eight children stopped using the tube or used it less often as they began to feed orally.

\section{Communication}

At discharge, $55 \%$ of the children could communicate orally, $27 \%$ were too young to speak and the remaining children used other forms of communication (Tables III, IV). At the time of study, most of the children $(71 \%)$ were still communicating orally, while $12 \%$ were still too young. The largest change in communication form was with the use of the one-way speaking valve ( $2 \%$ of the population at 
TABLE III

Communication

TABLE IV

Outcome of 24 patients who were too young to speak at discharge

\begin{tabular}{lc}
\hline Outcoine & Patients \\
\hline Still too young to speak at time of study & 8 \\
Oral speech with one-way speaking valve & 5 \\
Normal oral speech with no aid & 4 \\
Oral speech with one-way speaking valve and sign language & 1 \\
Normal oral speech with sign language & 1 \\
Sign language only & 1 \\
Died, lost to follow-up or weaned & 4
\end{tabular}

*Some subjects currently use more than one method.

discharge compared with $15 \%$ now). Most of the children (71\%) who were first ventilated before 3 years of age speak orally today, either independently or with the one-way speaking valve. However, an even larger proportion $(89 \%)$ of patients first ventilated after age 3 could speak orally at the time of the study.

The large increase in the use of oneway speaking valves in the entire group of patients is largely explained by the inclusion of children who were too young to speak and then began using it. Two patients with $\mathrm{SCl}$ started using the oneway speaking valve after speaking orally unaided for a time. One patient with an $\mathrm{SCI}$ exchanged an augmentative device for the valve. Only one patient stopped using the one-way speaking valve. Just four patients communicating at the time of discharge changed their mode of communication (two stopped using an augmentative device, one started using one, and one patient stopped using the valve) (see Tables III, IV).

\section{Education}

Although formal testing was not done at the time of the study, $65 \%$ of the children were neurodevelopmentally normal by clinical estimation; $12 \%$ had a mild to moderate delay with no discrete underlying neurological syndrome. $12 \%$ were too young to assess at the time of the study and the remainder had either cerebral palsy, autism, myelodysplasia, Down syndrome or a traumatic brain injury.

At discharge, $82 \%$ of the children were involved in a school program, with the largest group (29\%) involved in an earlyintervention program; $20 \%$ were in a class for those with physical or other impairments; $16 \%$ attended a regular classroom (Table V). At the time of the study, almost half as many again, double the percentage, of the children were in a regular school class (33\%); $24 \%$ were in a class for those with physical or other impairments, and substantially fewer (16\%) were in an early-intervention program. Six patients were using the ventilator when they graduated from high school, 


\begin{tabular}{lcc} 
& At discharge $(N=86 *)$ & Currently $(N=67 *)$ \\
\hline Not in formal school program & 15 & 8 \\
Early-intervention program & 25 & 10 \\
Regular pre-school & 4 & 2 \\
Physically or otherwise health-impaired & 17 & 16 \\
Regular classroom & 14 & 22 \\
Homebound & 7 & 3 \\
Other program & 4 & 6 \\
\end{tabular}

* Information on educational programs was not available for some subjects.

and several have begun taking college classes (see Table V).

\section{Mobility and ventilator transport}

At discharge, about a quarter of the children $(24 \%)$ could walk either alone, with braces or with a walker. Over a third of the patients $(35 \%)$ used a power wheelchair; $14 \%$ used both a power and a manual wheelchair; $17 \%$ had only a manual wheelchair and $9 \%$ were infants who were transported by stroller. Only 19 of the patients have had a change in mobility status since initial discharge. Nine of these switched between power and manual wheelchairs, or have purchased an additional chair as a supplement. Six of them were too young at discharge to need an aid to mobility, one was a child with myopathy who progressed from a walker to a power chair and three were children who had been transported in strollers and who then either began to walk or received wheelchairs.

Almost a third of the patients did not need to transport their ventilators on a regular basis, since the ventilators were only used at night. Nearly half the patients transported the ventilator mounted on the wheelchair, $11 \%$ with their stroller and $11 \%$ with their cart.

\section{Resources}

Most of the children $(61 \%)$ received aid from the state through Children's Special Health Care Services (CSHCS). Almost half $(46 \%)$ had some form of private health insurance, most commonly Blue Cross/Blue Shield; 19\% were receiving Medicaid; 19\% were covered by no-fault automobile insurance.

\section{MEDICAL OUTCOME \\ Mortality}

Twelve of the patients $(13 \%)$ have died six from progression of the underlying condition (Duchenne muscular dystrophy, Zellweger syndrome, chronic restrictive lung disease and amyotrophic lateral sclerosis), three because of ventilator malfunction or disconnection which resulted in anoxic encephalopathy, two from seizures of unknown etiology and one who dealt with all the necessary legal issues and had himself removed from the ventilator (Maynard and Muth 1987). The patients who died had been ventilated at home for an average of 2.0 (range 0.1 to 2.9 ) years. Their average age at the initiation of ventilation was 10.2 (range 0 to 19.1 ) years.

\section{Weaning}

Four patients were weaned, three from IPPV with tracheostomies, and one from a cuirass. Their primary diagnoses were BPD, acquired central hypoventilation, SCI and cardiac transplant. They used the ventilator at home for an average of 1.0 (range 0.2 to 2.9 ) years. At the time of the study, they have been breathing without a ventilator for an average of 3.9 (range 1.6 to 6.3 ) years. Their average age at the initiation of ventilation was 4.1 (range 0 to 13.6) years. One patient was weaned and decannulated without our knowledge or recommendation. He subsequently needed another tracheostomy 
and resumed long-term ventilator dependence when hospitalized for a viral infection.

\section{Hospital admissions following initial discharge}

Almost half of the children $(47 \%)$ were re-admitted to our hospital after initial discharge, averaging 1.7 (range 0.1 to 10 ) re-admissions per year since discharge. They have spent an average of 21.4 (range 0.5 to 118) days per year in the hospital. The most common cause of readmission was a need for surgery (58\%), followed by respiratory infection (56\%), illness (caused by rotavirus, gastrointestinal viruses, bacteremia) (42\%), rehabilitation $(31 \%)$ and other problems (24\%). The children also spent the most days per year in hospital for surgery (8.2 days), followed by respiratory problems (7.6 days). In the number of re-admissions per year for a particular cause, however, viral illness and bacterial infection excluding respiratory complications were the most frequent ( 0.6 admissions per year per patient), followed by respiratory problems ( 0.5 admissions per year per patient) (see Table I). The average number of days hospitalized per year was greatest for the children first ventilated under age 3 years and least for those patients first ventilated after 18 years of age. By the $t$ test, the average number of days in hospital per year per child initially ventilated before age 3 years was significantly greater than the average for the children initally ventilated after age 3 $(p<0.05)$.

We did not find a correlation using the $t$ test between the severity of neurodevelopmental delay and the number of hospitalizations. The diagnosis with the greatest percentage of patients being readmitted was neuropathy. The diagnosis with the greatest average number readmissions was BPD (3.4 re-admissions per year) (see Table I).

\section{Discussion}

There is a common misconception among health-care professionals and the community as a whole that ventilator-assisted children are medically unstable and critically ill. We believe that this review refutes this misconception. Paradoxi- cally, although this study was begun in order to produce a better definition of this population and how it changes over time, it was quickly discovered that for most variables there is very little change. When children are provided with appropriate rehabilitation and long-term planning at discharge, few patients have extreme changes in their medical status or ability to perform functional activities. The few changes in functional ability that did take place were usually a result of an improvement in the patient's medical status or growth and maturity. With appropriate rehabilitative follow-up. there was almost always an overall increase in function.

TRENDS IN AGE, DIAGNOSIS AND HOSPITALIZATION

An interesting trend found in the data was that the younger children had the greatest number of rehospitalizations and required the longest initial hospital stay. There may be several causes for this: (1) the diagnoses of the younger children (BPD, congenital anomalies, etc.) were usually more acute and unstable for longer periods of time (as opposed to myopathies and $\mathrm{SCI}$ ), and (2) the care plan for these children was generally more complex. Nutritional needs were often more difficult to meet and the inability to communicate verbally neccessitated more constant and careful observation of their health-care status. However, the question of the long-term outcome of children ventilated at such a young age is uncertain in this study, as these children have not been using home mechanical ventilation for long enough to allow us to draw any solid conclusions.

We also noted a decrease in the length of the initial hospital stay. Conclusions are somewhat difficult to reach, as a confounding variable was the unequal representation of various diagnoses over time. However, the trend may be attributable to several factors. In the past 15 years, the team has become more efficient at coordinating services for these children. The recent establishment of the stable ventilator unit has contributed to this efficiency by getting the children out of intensive care into a more home-like setting, making discharge planning easier. 
Secondly, the community is better prepared to accept such children. Finally, as home mechanical ventilation becomes more recognized and advances in technology improve quality of life, patients with progressive diseases - who years ago would have forgone the institution of mechanical ventilation - now often choose to prolong their lives. Such patients have a much shorter hospital stay, because the only acute problem is respiratory failure.

\section{TRENDS IN MODE OF VENTILATION}

Improvements in technology have affected our patient population directly. We use negative pressure ventilation much less frequently since bi-level positive pressure ventilation by face mask is being used. There has been poor patient compliance with the pneumowrap, and scoliosis makes using the cuirass difficult. In contrast, the face-mask system is much more comfortable, and remains flexible as the child grows.

\section{TRENDS IN ACTIVITIES OF DAILY LIVING Nursing}

A major contributor to stress cited in the literature (Aday et al. 1989, Hazlett 1989) is that home nursing destroys the family's privacy. This also seems to be true in our patient population. During the discharge process, one of the goals is to train the families thoroughly in the child's care so that extensive nursing hours are not always necessary. Some of the children, too, as they grow older become more functional and are able to perform much of their own care (e.g. suctioning and catheterization). A few families have opted to have no outside nursing care, performing it all themselves. In most of these cases, however, we recommend that they have at least a few hours per day to prevent family burn-out (Aday et al. 1989, Hazlett 1989, Quint et al. 1990).

It was predicted and affirmed that the children with tracheostomies and IPPV would have more nursing hours than those using other types of ventilation. However, we were proved wrong in our prediction that the age-group with the greatest number of nursing hours would be the youngest children, correlating with their longer length of hospital stay and greater number of rehospitalizations. The youngest and oldest children had similar numbers of in-home nursing hours, while the 9- to 12-year-old children had the most. There may be two factors at work here: (1) the children aged between 9 and 12 years also had more days per year in the hospital after initial discharge, and (2) half of the children aged 9 to 12 have myopathy, and this particular time in the disease course is when many changes are taking place in terms of loss of function.

Another pattern in nursing hours was related to diagnosis. The patients with the most nursing hours were those with SCI, who have many functional needs apart from mechanical ventilation. The diagnoses dominated by respiratory problems or apnea with fewer associated deficits (BPD and CCHS) had a wide variability in number of nursing hours. The more unstable children (those with BPD) had many more nursing hours than those with CCHS, reflecting the fact that medical instablity and the severity of respiratory compromise are just as closely correlated with nursing hours as the number of deficits in function.

\section{Nutrition}

Very few of the patients required tube placement after initial discharge, as feeding problems were usually managed during the initial hospitalization. We act conservatively with gastrostomy tubes, usually leaving them in place even when the child has developed an adequate oral intake: this prevents nutritional deficits and dehydration if the child becomes ill, often preventing a hospitalization.

\section{Communication}

After initial discharge, very few of the patients required speech therapy to maintain their ability to communicate. Other authors have described deficits in language ability for children with tracheostomies in infancy, saying that although many of the children can speak, they speak less than other children their age (Aradine 1983). However, most of the children that we followed learned to speak orally. During the initial hospitalization, we always strive to provide the patient with the optimal form of communication 
that will grow with his or her needs. We have also seen a large increase in the use of the one-way speaking valve to aid young patients in speaking. This appears to often be replacing augmentative devices in facilitating communication. Clearly, advances in technology have a large impact on this population.

\section{Education}

An important part of discharge planning is a cognitive assessment and choice of appropriate placement in a school program, including all of the necessary arrangements for transportation and nursing. Members of the team participate in the individual education planning meeting held by the school district to accomplish these goals. In addition, the state provides an early-intervention program for children up to 3 years of age, through which these children receive services. For children who are cognitively normal. it is strongly suggested that their placement be in a regular education classroom. Several school-aged patients have opted for homebound schooling, although we discourage this as it precludes the healthy development of social skills and formation of peer relationships. As our population grows older, they graduate from high school as planned, and several have continued on to college classes: a testimony to the abilities of these patients when they are given appropriate services.

\begin{abstract}
Mobility
Mobility was another very stable factor in these children's lives: when a high-quality adjustable wheelchair appropriate to the child's current and future needs was provided at discharge, little further change was necessary apart from periodic repairs and replacement for growth. The largest contributor to changes in mobility status was a patient's obtaining a second chair or the need of a young child for a chair after having outgrown a stroller.
\end{abstract}

\section{Resources}

The literature cites financial concerns as being a major contributor to stress in the families of such patients as ours (Aday et al. 1989, Hazlett 1989, Wegener and Aday 1989). Although the types of financial assistance for the families remained relatively stable, we believe this to be one of the largest contributors to stress in the patients and families. Most of our patients under the age of 21 years receive funding from the state through CSHCS, and over the age of 18 years they have the benefit of coverage through Medicaid. Michigan also has the advantage of nofault automobile insurance laws: there is coverage for those patients injured in motor vehicle accidents for medically necessary interventions required to fulfill their needs for rehabilitation and continuing health care. Where resources are limited, we are often able to adjust facets of the patient's care plan. Several patients hire aides whom they train themselves when they cannot afford full-time nursing care, and in families covered by automobile insurance, parents may act as the caregivers in place of nurses to receive funding for incidental costs and the financial burden often incurred when jobs are put on hold due to the child's disability. Despite this, however, financial considerations are a continuing problem for most of these families, and have an impact on almost every aspect of the child's rehabilitation and health care.

\section{TRENDS IN MEDICAL OUTCOME}

There was no correlation between death or weaning from ventilation with any parameter measured. Many patients have progressive illnesses, and most will never be completely weaned due to a permanent injury. The goal is to ventilate them as needed to keep them healthy and functional; the least ventilation is not necessarily the best. In addition, there was no significant difference in medical outcome between those with congenital disorders vs those with acquired disorders, nor was there a medical outcome difference correlated with level of cognitive and neurodevelopmental impairment.

One noticeable trend was in the pattern of hospitalizations. The effort to fulfill the children's rehabilitation needs during the initial hospitalization appears successful. as the number of re-admissions for rehabilitation reasons was the lowest of any of the listed causes, with less than a third of the patients ever being admitted for this reason. Just over half of the patients were ever admitted for respiratory reasons. 
with this averaging only once every 2 years: evidence that with proper followup and family training, these children can remain remarkably healthy in the normal school and home environments.

\section{RECOMMENDATIONS}

The environment into which a ventilatorassisted child is discharged and the child's condition at discharge and afterwards are dynamic and must be monitored by the health-care team. With appropriate rehabilitation during the initial hospitalization, future health problems and changes in functional status can be minimized. It is a misconception shared by many health-care professionals as well as the public - that the ventilator- assisted child is medically fragile and unstable. We conclude that with complete and comprehensive rehabilitation during the initial hospitalization and careful management and supervision during follow-up, ventilator-assisted children can lead productive and fulfilling lives with their families.

Accepted for publication 25th May 1995.

Authors' Appointments

Virginia S Nelson, MD, MPH:

Julic C Carroll, BA:

Edward A Hurvitz, MD:

Department of Physical Medicine and Rehabilitation,

University of Michigan Medical Center, Ann Arbor. Michigan, USA.

Janet M Dean. MS. RN, CSPNP. The Children's Mercy Hospital, Kansas City, Missouri.

*Correspondence to first author.

\section{SUMMARY}

The medical records of 89 ventilator-assisted children followed at the University of Michigan Medical Center from 1978 to 1993 were reviewed. The status of these children was remarkably stable. Parameters of communication, nutrition, education, and mobility changed very little over time, and fewer than half had to be re-admitted. Children aged 9 to 12 years had the most nursing hours; in terms of diagnosis, those with spinal cord injury and bronchopulmonary dysplasia had the most. The younger children had the longest initial hospital stay and the most re-admissions. The authors conclude that appropriate rehabilitation during the initial hospitalization can minimize later changes, instability and rehospitalizations, and that careful follow-up and periodic evaluation can improve the patients' health and function.

\section{RÉSUMÉ}

Ventilation assistée à domicile che: l'enfant: paramètres d'une évolution durant quinze ans d'expériencé

Les dossiers médicaux de 89 enfants ayant bénéficié d'une ventilation assistée et suivis par le Centre Médical de l'Université du Michigan entre 1978 et 1993 ont été examinés. L'état de ces enfants est apparu remarquabiement stable. Les paramètres de communication, alimentation. éducation et déplacements évoluèrent très peu et moins de la moitié des enfants devaient être réhospitalisée. Les enfants de 9 à 12 ans exigeaient le plus d'heures d'infirmière; de même, en terme de diagnostic, les enfants avec lésions de la moelle épinière ou une dysplasie bronchopulmonaire. Les enfants les plus jeunes exigeaient le temps hospitalier initial le plus long et les réhospitalisations les plus fréquentes. Les auteurs concluent qu'une prise en charge appropriée durant l'hospitalisation initiale peut atténuer les modifications ultérieures, l'instabilité ou la réhospitalisation, et qu un suivi soigneux et des évaluations périodiques peuvent améliorer la santé et les capacités des patients.

\section{ZUSAMMENFASSUNG}

Heimbeatmung von Kindern: Veränderungen nach 15 Jahren Eıfahrung.

Die Krankengeschichten von 89 Kindern mit assistierter Beatmung, die von 1978 zu 1993 in der Universitätsklinik von Michigan betreut wurden, sind durchgesehen worden. Der Zustand dieser Kinder war bemerkenswert stabil. Die Parameter für Kommunikation, Ernährung . Erziehung und Mobilität änderten sich in diesem Zeitraum kaum und weniger als die Hälfte mußten wieder aufgenommen werden. Kinder im Alter zwischen 9 und 12 Jahren brauchten die meisten Pflegestunden, unter Berücksichtigung der Diagnose hatten Kinder mit Rückenmarksverletzungen und bronchopulmonaler Dysplasie die meisten. Die jüngeren Kinder waren am längsten in der Klinik und mußten am häufigsten wieder aufgenommen werden. Die Autoren schließen daraus, daß eine ausreichende Rehabilitation beim ersten Krankenhausaufenthalt spätere Veränderungen, Instabilitäten und Rehospitalisierungen reduzieren und sorgfältige Kontrollen und periodische Beurteilungen die Gesundheit und Funktion der Patienten verbessern können. 
Center de la Universidad de Michigan desde 1978 a 1993. El estado de estos niños era notablemente estable. Los parámetros de comunicación, nutrición, educación y movilidad cambiaron muy poco a lo largo del tiempo y sólo tuvieron que reingresar menos de la mitad de ellos. Los niños de 9 a 12 años tenían el mayor número de horas decuidados y en términos de diagnóstico los niños con lesión medular y displasia broncopulmonar necesitaban el máximo de cuidados. Los niños más pequeños presentaban el estadio inicial hospitalario más largo y el mayor número de reingresos. Los autores concluyen que una apropiada rehabilitación durante el inicio de la hospitalización puede minimizar los cambios posteriores, la inestabilidad y las rehospitalizaciones. Igualmente un seguimiento cuidadoso y evaluaciones periódicas pueden mejorar la salud y la función de los pacientes.

References

Aday LA. Wegener DH, Andersen RM. Aitken MJ. (1989) Home care for ventilator-assisted children. Health Affairs 8: 137-47.

American Thoracic Society. (1989) Home mechanical ventilation of pediatric patients. American Review of Respiralory Disorders 141: 258-9.

Aradine CR. (1983) Young children with tracheostomies: health and development. Westem Journal of Nursing Research 5: 115-27.

Bach JR. (1991) Life satisfaction of individuals with Duchenne muscular dystrophy using long-term mechanical ventilatory support. American Jourmal of Physical Medicine and Rehabilitation 70: 129-35.

Frates RC, Splaingard ML, Smith EO, Harrison MD. (1985) Outcome of home mechanical ventilation in children. Jourmal of Pediatrics 106: 850-6.

Gilgoff IS, Kahlstrom E. MacLaughlin E, Keens TG. (1989) Long term ventilatory support in spinal muscular atrophy. Joumal of Pediatrics 115: $904-9$.

Gillis J. Tibballs J. McEnicry J, Heavens J, Hutchins P. Kilham HA, Henning R. (1989) Ventilatordependent children. Medical Journal of Australia 150: $10-14$

Goldberg AI. (1986) Home carc for life-supported persons: is a national approach the ansiver? Chest 90: 744-8.

- Frownfelter D. (1990) The ventilator-assisted individuals study. Chest 98: 428-33.

- Monahan CA. (1989) Home health care for children assisted by mechanical ventilation: the physician's perspective. Journal of Pediatrics 114: $378-83$.

Hazlett DE. (1989) A study of pediatric home ventilator management: medical. psychosocial, and financial aspects. Jourmal of Pediatric Nursing 4: 284-94.

Koop CE. (1983) Mecting the health care needs of children with disabilities. Public Heallh Reports 98: 105-7.

Make BJ. (1986) Long-term management of ventilator-assisted individuals: the Boston University experience. Respiratory Care 31: 303-10.

Marcus CL. Jansen MT. Poulsen MK. Keens SE. Nield TA, Lipsker LE, Keens TG. (1991) Medical and psychosocial outcome of children with congenital central hypoventilation syndrome. Journal of Pediatrics 119: 888-95

Maynard FM. Muth AS. (1987) The choice to end life as a ventilator-dependent quadriplegic. Archives of Phisical Medicine and Reliabilitation 68: $862-4$.
Merkens MJ, Perrin EC, Perrin JM, Gerrity PS (1989) The awareness of primary physicians of the psychosocial adjustment of children with a chronic illness. Journal of Behavioral and Developmental Pediatrics 10: $1-10$.

Peters SG, Viggiano RW (1988) Home mechanical ventilation. Mavo Clinic Proceedings 63: 1208-13

Plummer AL, O'Donohuc WJ. Petty TL. (1989) Consensus conference on problems in home mechanical ventilation. American Review of Respiratorn Disorders 140: 555-60.

Purtilo RB. (1986) Ethical issues in the treatment of chronic ventilator-dependent patients. Archiives of Phrsical Medicine and Rehabilitation 67: 718-21.

Quini RD, Chesterman E, Crain LS, Winkleby $M$, Boyce T. (1990) Home care for ventilator-dependent children. American Jourmal of Diseases of Children 144: 1238-41

Sivak ED. Cordasco EM. Gipson WT. Mehra A. (1986) Home care ventilation: the Cleveland Clinic experience from 1977 to 1985 . Respirator: Care 31: 294-302.

Splaingard ML. Frates RC. Harrison GM. Carter RE. Jefferson LS. (1983) Home positive-pressure ventilation: twenty years experience. Chest 84: 376-82.

Stcin REK. Jessop DJ. (1984) Does pediatric home care make a difference for children with chronic illness? Pediatrics 73: 845-53.

Strumpf DA. (1990) An evaluation of the Respironics BiPAP bi-level CPAP device for delivery of assisted ventilation. Respiratory Care 35: 415-22

Thompson CL. Richmond M. (1990) Teaching home care for ventilator-dependent patients: the patients' perception. Heart and Limg 19: 79-83.

Waldhorn RE. (1992) Nocturnal nasal intermittent positive pressure ventilation with bi-level positive airway pressure (BiPAP) in respiratory failure. Chest 101: 516-21.

Warzak WJ. Engel LE. Bischoff LG. Stefans VA (1991) Developing anxiety-reduction procedures for a ventilator-dependent pediatric patient. Archives of Physical Medicine and Rehabilitation 72: 503-7.

Wegener DH, Aday LA. (1989) Home care for ventilator-assisted children: predicting family stress. Pediatric Nursing 15: $371-6$.

White KD. Perez. PW. (1986) Your ventilator patient can go home again. Nursing 12: $5+6$.

Whitford KM. (1988) Health care needs of ventilator-dependent children. Pediatric Nursing 14: $216-9$ 